\title{
Anàlisi del moviment de coets d'aigua
}

\author{
Basili Martínez Espinet \\ IES Miquel Martí i Pol (Roda de Ter) \\ bmartine@xtec.cat
}

S'estudia el moviment d'un coet d'aigua a partir de la seu enregistrament en vídeo $i$ s'analitza matemàticament la seva trajectòria per establir-ne les característiques.

Paraules clau: cinemàtica, dinàmica, vídeo, Multilab, coets d'aigua

\section{Introducció}

Els coets d'aigua estan fets amb ampolles de plàstic d'aigua d'un litre i mig o bé amb botelles de dos litres de refresc amb gas.

Només els hi hem de posar una punxa aerodinàmica i unes aletes estabilitzadores construïdes amb cartolina i ja tenim llest el coet (fig. 1).

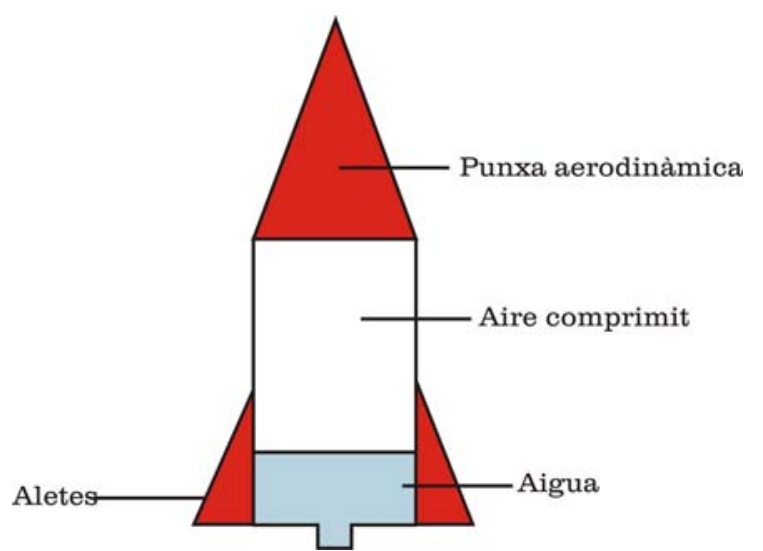

Figura 1. Estructura del coet.

S'omple amb una mica d'aigua i es llança amb la pressió que proporciona una manxa de bicicleta o un compressor.

Per als dos tipus de coets hi ha dos tipus de llançadores que hem de mirar de construir nosaltres per assegurar l'èxit dels experiments.

En aquest article, farem un estudi del moviment del coet a partir d'un vídeo que hem enregistrat i editat amb l'ajut dels programes Multilab i Studio 8 que són a tots els instituts. També explicarem com construir les dues llançadores. Si no es coneixen aquests programes es pot fer un experiment més senzill -però també interessant- que consisteix en veure com varia l'altura màxima i el temps de vol variant el volum d'aigua. (És aconsellable provar amb quantitats de líquid que vagin del 20 al 30\% del volum de la botella).

A partir d'aquestes experiències es poden introduir i explicar els conceptes de la tercera llei de Newton, la segona llei, la dependència de la fricció amb la velocitat, la relació entre pressió i temperatura a volum constant, l'expansió adiabàtica i també alguns conceptes de mecànica de fluids a partir de l'equació de Bernouilli.

En alguns països com el Regne Unit i els Estats Units es fan competicions d'aficionats o professionals on l'única restricció és que els coets no poden portar cap peça metàl-lica i han d'estar impulsats només per aigua i aire. Les altures que assoleixen i els temps de vol són realment espectaculars.

\section{Construcció dels coets}

Per construir els coets necessitem una botella d'aigua o de refresc buida, una cartolina, tisores, cola i precinte.

Per fer la punxa dibuixem un tros d'arc amb el compàs i l'enganxem amb cola i amb precinte al cos del coet. Convé que la punxa tingui una longitud una mica més gran que la meitat de l'alçada de la botella per reduir el coeficient aerodinàmic. 
Podem fer tres aletes estabilitzadores com les de la figura 2. Les enganxarem amb precinte amb una separació entre elles de $120^{\circ}$. Els coets els podem fer a classe o els poden fer els alumnes a casa seva.

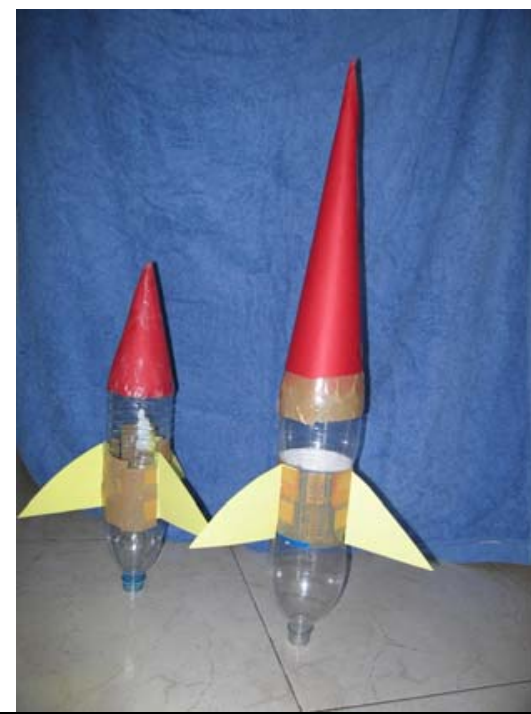

Figura 2. Els dos tipus de coets: amb ampolla de litre i mig o de dos litres.

\section{Construcció de les llançadores}

A. Per fer la llançadora de les botelles d'un litre i mig, que tenen el coll amb un diàmetre interior de $26 \mathrm{~mm}$, necessitem un tap de goma dels que s'utilitzen al laboratori, i l'agulla metàl-lica que acoblem a la manxa per inflar pilotes. Fem un forat al tap amb un clau i ja tenim la llançadora a punt. (Cal tenir agulles de reserva ja que de vegades es trenquen).
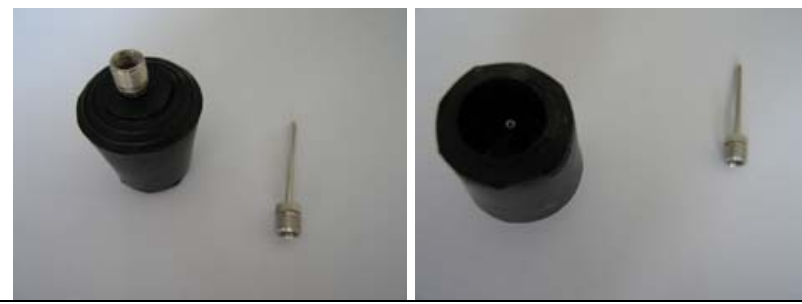

Figura 3. Fotografies de la llaçadora més senzilla.

B. La segona llançadora (fig. 4) s'anomena llançadora Clark, en honor al seu descobridor australià. És una mica més complexa però els resultats també són millors. Per a aquesta llançadora hem d'utilitzar botelles de refresc amb un coll de $22 \mathrm{~mm}$ de diàmetre interior. El material necessari, que es compra als magatzems que subministren als llauners, és: 3 metres de tub de PVC de mitja polzada, un colze de $90^{\circ}$ i un tap per al tub, brida metàl-lica, 10 subjectadors de cable, cola de PVC (Tangit), una vàlvula de neumàtic de cotxe i cinta aïllant.

A la direcció d'Internet

http://www.cienciafacil.com/Lanzadordecohetes.ht $\mathrm{ml}$

hi podeu trobar la descripció del procés pas a pas. A sota podeu veure la llançadora que varem fer a l'IES.

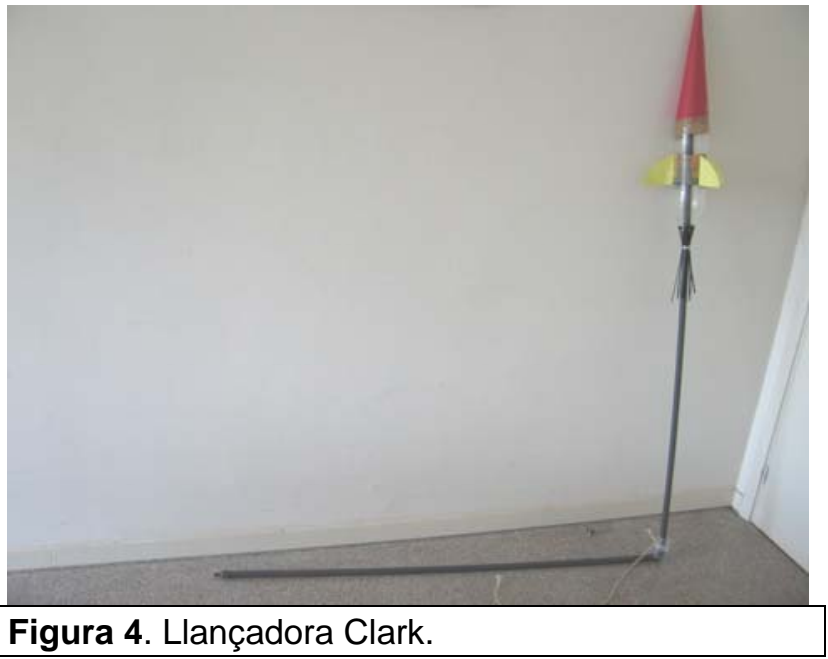

\section{Vídeos de llançaments}

[El lector pot veure dos vídeos de llançaments des de la secció Suplements d'aquest número de Ciències]:

Video1 Video2

\section{Fonaments físics. Dinàmica del moviment}

En aquest moviment en l'etapa d'acceleració hi actuen tres forces en tot moment: la força motriu que proporciona l'aire comprimit i és a l'eix y amb sentit positiu, la força de fregament i la força pes, ambdues en el mateix eix però amb sentit negatiu.

Si hi apliquem la segona llei de Newton tenim:

$$
\frac{d(m v)}{d t}=\mathrm{F}_{\text {motriu }}-\mathrm{F}_{\text {fregament }}-\mathrm{F}_{\text {pes }}
$$

on $m$ és la massa puntual $(\mathrm{kg})$ del coet i $v$ la seva velocitat vertical $(\mathrm{m} / \mathrm{s})$.

Aplicant la regla de la cadena al terme de l'esquerra quedarà 


$$
m \frac{d v}{d t}+v \frac{d m}{d t}
$$

La força motriu la definim com

$$
v_{\text {escapament }} \frac{d m}{d t}
$$

on $v_{\text {escapament }}$ és la velocitat d'escapament de l'aigua $(\mathrm{m} / \mathrm{s})$.

La força de fregament a aquestes velocitats es relaciona amb la velocitat segons

$$
F_{\text {fregament }}=b v^{2}
$$

on $b$ és un coeficient experimental normalment superior a 1.

La força pes és mg, on $m$ és la massa puntual del coet i $g$ val $9,81 \mathrm{~m} / \mathrm{s}^{2}$. L'equació queda així:

$$
m \frac{d v}{d t}=v_{\text {escapament }} \frac{d m}{d t}-v \frac{d m}{d t}-b v^{2}-m g
$$

El terme

$$
v \frac{d m}{d t}
$$

és negligible respecte del primer ja que per la conservació de la quantitat de moviment la velocitat d'escapament és molt més gran que la velocitat del coet. L'expressió es transforma en

$$
m \frac{d v}{d t}=v_{\text {escapament }} \frac{d m}{d t}-b v^{2}-m g
$$

Si apliquem l'equació de Bernouilli de la conservació de l'energia en fluids a l'instant inicial del llançament (ometent el terme de l'energia potencial), tindrem

$$
\frac{P_{\text {int }}-P_{a t}}{d_{\text {aigua }}}+\frac{v_{\text {sup }}^{2}-v^{2} \text { escapament }}{2}=0
$$

on $P_{\text {int }}$ i $P_{\text {at }}$ són respectivament la pressió dins de l'ampolla i la pressió atmosfèrica, ambdues expressades en $P a$.

$\mathrm{V}_{\text {sup, }}$ es la velocitat del nivell superior de l'aigua dins de la botella i és negligible davant de $v_{\text {escapament }}$ de manera que al final queda:

$$
\frac{P_{\text {int }}-P_{a t}}{d_{\text {aigua }}}+\frac{v_{\text {escapament }}^{2}}{2}=0
$$

Si tenim en compte que

$$
\frac{d m}{d t}=d_{\text {aigua }} \cdot S_{\text {coll }} \cdot v_{\text {escapament }}
$$

-on $\mathrm{S}_{\text {coll }}$ és la secció del coll de l'ampolla en $\mathrm{m}^{2}$ substituint ens quedarà finalment

$$
F_{\text {motriu }}=2\left(P_{\text {int }}-P_{\text {at }}\right) S_{\text {coll }}
$$

A partir d'aquesta expressió ja podem fer consideracions pràctiques amb els alumnes en els dos tipus de coets, ja que coneixem la secció del coll i la pressió interior en el moment del llançament (ens la marca el manòmetre de la bomba).

La pressió interior de l'ampolla es considera que varia seguint l'expressió de l'expansió adiabàtica (sense temps per intercanviar calor amb l'exterior):

$$
P_{\text {int }}=P_{a t}\left(V_{0} / V\right)^{k}
$$

on $V_{0}$ i $V$ són els volums inicial i instantanis respectivament en $\mathrm{m}^{3}$, i $k$ el coeficient adiabàtic de l'aire, que val 1,4

\section{ESTUDI DEL MOVIMENT DEL COET (VÍDEO 2)}

\section{Introducció}

L'estudi del moviment d'aquest coet és útil per explicar la tercera llei de Newton. L'experiència és espectacular ja que arriben a altures d'uns $130 \mathrm{~m}$. Nosaltres farem un estudi del vídeo 2 de l'exemple, que puja uns $40 \mathrm{~m}$. Al tenir la càmera fixa, si el coet puja molt s'hi veu molt petit i es fan molts errors quan es mesuren els fotogrames per analitzar el moviment.

En la trajectòria del coet hi ha dues fases: una d'acceleració que dura mentre hi ha aigua i l'altra que seria un tir parabòlic. Farem un estudi del moviment del coet fent servir els programes Multilab i Studio 8, de l'aula de les noves tecnologies per ciències. 


\section{Objectius}

1) Construir el coet i comprovar el seu funcionament. Entendre el paper de la tercera llei de Newton en aquest procés.

2) Utilitzar els programes Studio 8 i Multilab per analitzar el moviment.

3) Esbrinar quina equació correspon a la primera etapa del moviment (pot ser que no sigui cap de les habituals).

4) Esbrinar si la segona etapa correspon a un tir parabòlic i veure si la fricció és significativa. (Si observem com cau una ampolla de plàstic buida des d'una altura de $30 \mathrm{~m}$, podem sospitar que el fregament pot ser important).

\section{Material per a l'anàlisi}

Càmera de vídeo. Cable fire-wire IEEE 1394, programes Studio 8 i Multilab.

\section{Hipòtesi}

El moviment té dues fases diferenciades: la primera correspon al temps que hi ha aigua dins de l'ampolla i l'acceleració és molt gran, mentre que la resta de temps correspon a un moviment parabòlic.

Però hem d'esbrinar si l'acceleració de frenada és de $9,8 \mathrm{~m} / \mathrm{s}^{2}$ o bé té un valor menor a causa de la fricció.

\section{Procediment experimental}

Omplim d'aigua un terç del volum de l'ampolla $(500 \mathrm{ml})$.Tanquem amb el tap que tenim preparat amb l'agulla d'inflar pilotes i procurem que quedi ben tapat.

Una persona ha d'aguantar el coet en posició vertical mentre que una altra ha de fer funcionar la manxa.

Encara una altra persona ha d'enregistrar el procés amb el vídeo que estarà sobre un trespeus.

Amb el cable fire-wire capturem el vídeo en l'ordinador, i l'editem amb el programa Studio 8. És millor passar el vídeo a format MPG per què l'AVI és molt més voluminós.

\section{Anàlisi de les dades}

Finalment obrim el programa Multilab i importem el vídeo del qual volem analitzar el moviment.
Si marquem el coet en cada fotograma obtenim el gràfic següent:

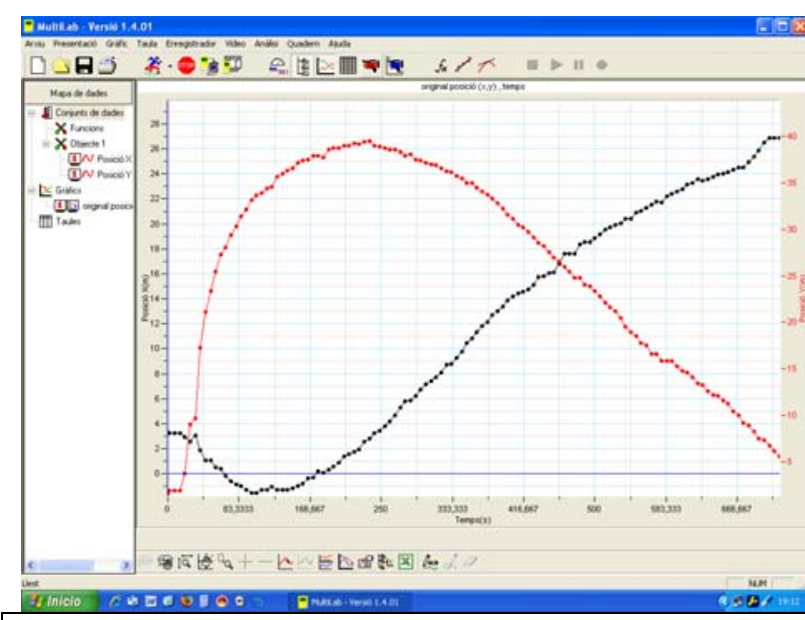

Figura 5. Variació al llarg del temps del valor de $x$ (en negre) i de $y$ (en vermell).

Podem observar que hi ha dues parts diferenciades. Les retallarem per fer una anàlisi de la posició i de la velocitat mitjançant la derivada.

La primera part amb més pendent correspon a l'etapa que hi ha aigua en el coet i l'acceleració és molt important. A la fig. 6 podem veure les gràfiques del retall de la posició i les seves equacions ajustades (entre $\mathrm{t}=0 \mathrm{it}=60 \mathrm{~s}$ aproximadament).

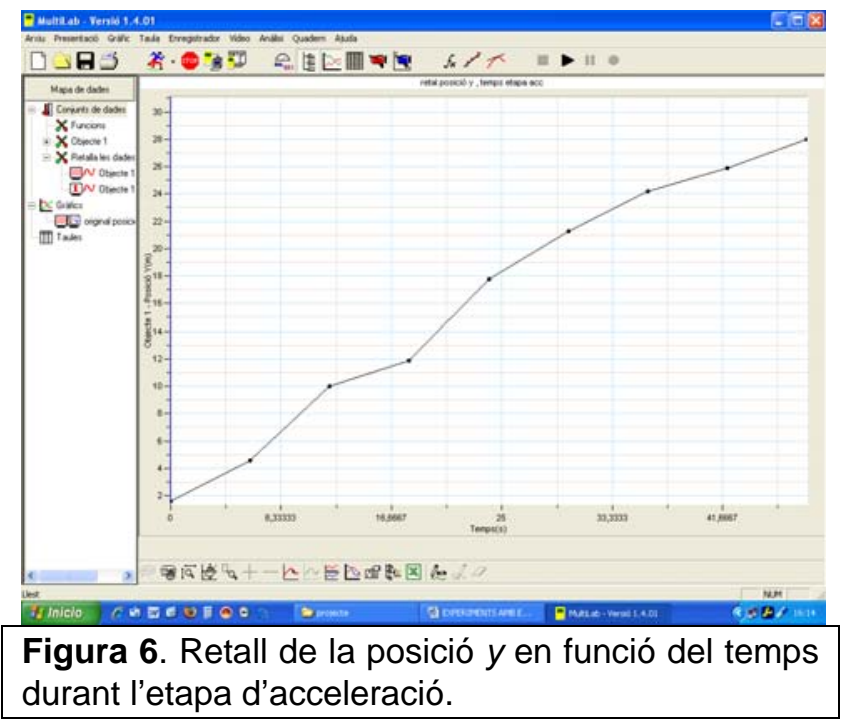

A la figura 7 podem veure en vermell la funció ajustada que correspon a un polinomi de grau 3 . El coeficient de regressió és de 1. 


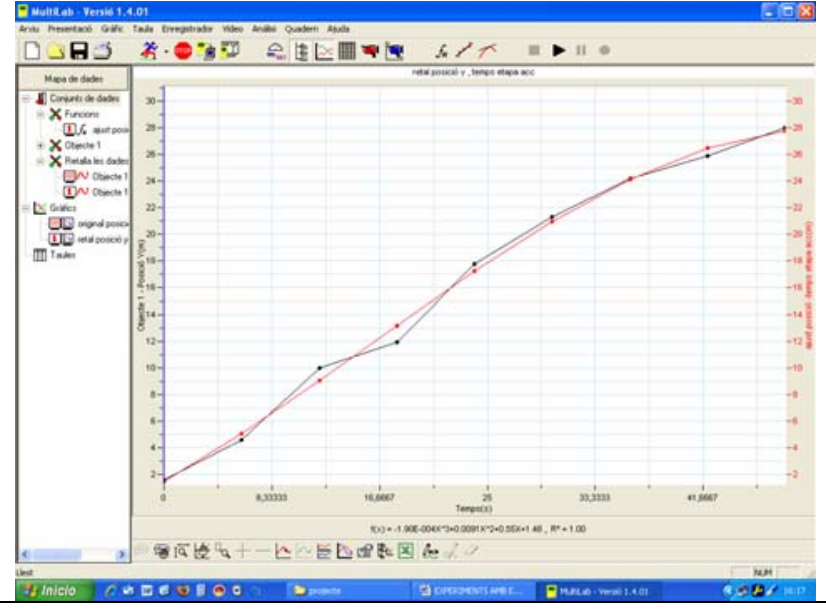

Figura 7. Ajustament de la posició y durant l'etapa d'acceleració.

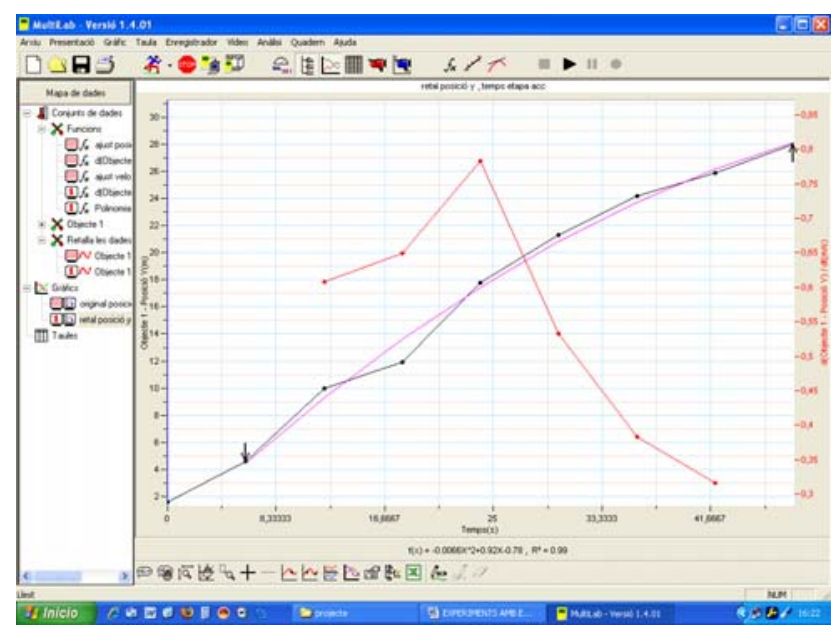

Figura 8. Ajustament de la velocitat y durant l'etapa d'acceleració.

A la fig. 8 podem veure en vermell la derivada de la posició en l'etapa d'acceleració. La funció ajustada és un polinomi de grau 2 i té un coeficient de regressió de 0,99.

A la fig. 9 veiem en negre la gràfica de la posició $y$ en funció del temps en l'etapa de tir parabòlic. I en roig es veu la funció ajustada que correspon a un polinomi d'ordre 2, que té un coeficient de regressió de 1.

\section{Conclusions}

Per comprovar si es compleix la hipòtesi farem servir les equacions ajustades. (En totes les equacions el temps està en segons/100).

En l'etapa d'acceleració he fet diverses proves d'ajustament i al final la posició y s'ajusta a un polinomi de tercer grau amb un $\mathrm{R}^{2}=1$.

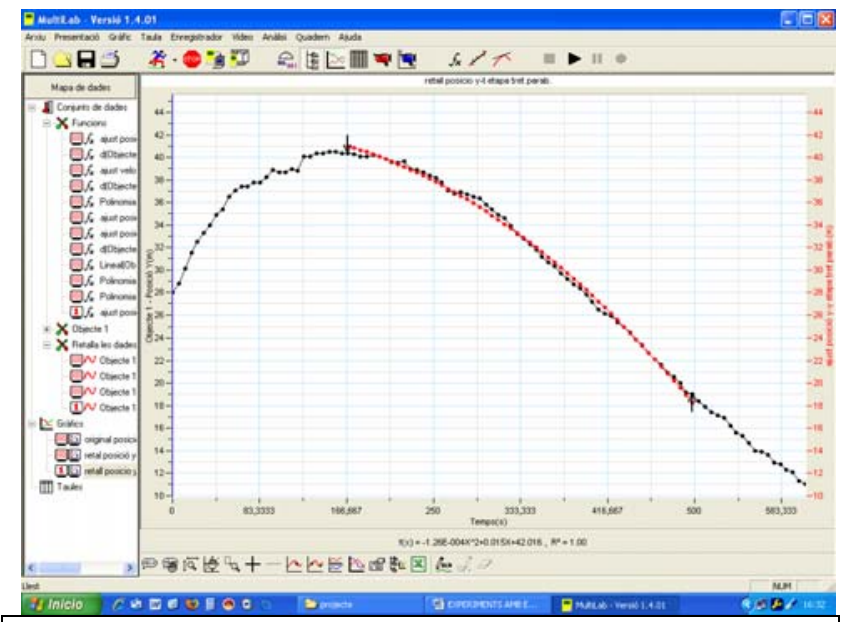

Figura 9. Retall de la posició y i ajustament en l'etapa de tir parabòlic.

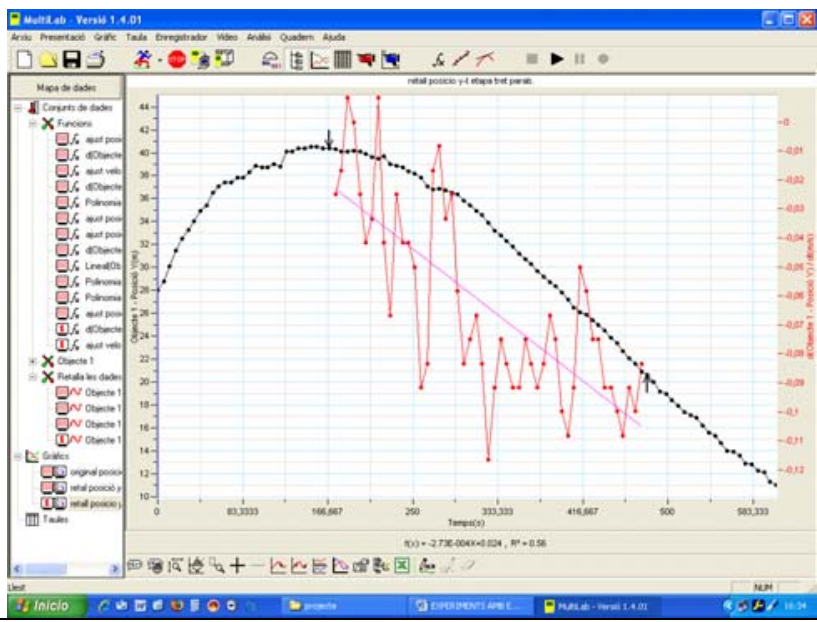

Figura 10. Ajustament de la velocitat $y$ durant l'etapa del tir parabòlic.

Les equacions ajustades obtingudes són les següents:

$$
\begin{gathered}
Y(t)=-1,9 \cdot 10^{-4} t^{3}+0,0091 t^{2}+0,55 t+1,48(m) \\
\left(R^{2}=1\right)
\end{gathered}
$$

L'equació de velocitat ajustada obtinguda en aquesta etapa és la següent:

$$
V_{y}(t)=-0,0066 t^{2}+0,92 t-0,78(\mathrm{~m} / \mathrm{s})
$$

$$
\left(R^{2}=0,99\right)
$$

Amb aquestes dades obtingudes podem estar bastant segurs que el moviment en l'etapa d'acceleració segueix una equació d'aquest tipus, ja que es sens dubte la que s'hi ajusta millor; el que ja és 
una mica més complex és interpretar els termes d'aquestes equacions.

En l'etapa posterior hem suposat que es compleixen les equacions del tir parabòlic tot i que si veiem el vídeo ens podem adonar que al final el vent desvia l'ampolla.

Les equacions de posició ajustades obtingudes en aquesta etapa són les següents:

$$
\begin{gathered}
Y(t)=-1,26 \cdot 10^{-4} t^{2}+0,015 t+42,06(m) \\
\left(R^{2}=1\right)
\end{gathered}
$$

L'equació de velocitat obtinguda en aquesta etapa és:

$$
V_{y}(t)=-2,73 \cdot 10^{4} t+0,024(\mathrm{~m} / \mathrm{s}) \quad R^{2}=0,56
$$

Aquests resultats ja no són tan perfectes com els anteriors; ho podem atribuir a l'efecte del vent que és més important quan la força impulsora és més feble. Quan les trajectòries entre fotograma i fotograma són més curtes es comet un error relatiu importat quan es marca l'objecte en moviment. De totes maneres, per les equacions de posició podem veure que el moviment és parabòlic i que la fricció i el vent no són negligibles.

Finalment, després d'analitzar diferents exemples podem dir que hi ha una etapa d'acceleració en la qual l'equació de la posició s'ajusta molt bé amb un polinomi de tercer grau i la de la velocitat amb un de segon grau.
Hi ha una segona etapa de moviment parabòlic durant la qual el fregament és important. Per identificar els coeficients d'ajustament amb els coeficients teòrics s'haurien de tenir en compte els errors de paral.latge i les unitats del temps, expressades en segons/100; de totes maneres sembla una tasca una mica complicada.

\section{BIBLIOGRAFIA}

AIAA - American Institute of Aeronautics and Astronautics.(1993). Aerospace Desing Enginers Guide, 3rd ed AIAA Washignton DC.

Adams.J.L.(1986). The care and Feeding of IdeasA Guide to Encouraging Creativity. Ed AddisonWesley.

Sutton,G.P. (1992). Rocket Propulsion Elements, 6th ed John Wiley \& Sons NY.

\section{Internet}

http://www.cienciafacil.com/Lanzadordecohetes.ht $\mathrm{ml}$

http://www.makerwiki.com/index.php/Cohete_de_a gua

http://www.geocities.com/josemi20002000/techie.ht $\mathrm{ml}$

http://www.ast.leeds.ac.uk/ knapp/rockets/

http://users.bigpond.net.au/mechtoys/waterrocket.ht $\mathrm{ml}$ 